Article

\title{
Inhibition of Bacterial and Fungal Biofilm Formation by 675 Extracts from Microalgae and Cyanobacteria
}

\author{
Virginio Cepas ${ }^{1}{ }^{1}$, Yuly López ${ }^{1}$, Yaiza Gabasa ${ }^{1}$, Clara B. Martins ${ }^{2}$, Joana D. Ferreira ${ }^{2}$, \\ Maria J. Correia ${ }^{2}$, Lília M.A. Santos ${ }^{2}$, Flávio Oliveira ${ }^{3}$, Vitor Ramos ${ }^{3}{ }^{\circ}$, Mariana Reis ${ }^{3}$,

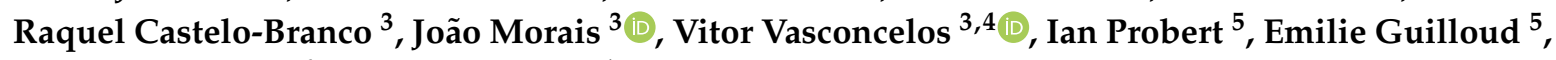 \\ Mohamed Mehiri ${ }^{6}$ and Sara M. Soto ${ }^{1, *}$ \\ 1 ISGlobal, Hospital Clínic-Universitat de Barcelona, 08036 Barcelona, Spain; \\ virginio.cepas@isglobal.org (V.C.); yuly.lopez@isglobal.org (Y.L.); gabasagyaiza@gmail.com (Y.G.) \\ 2 Coimbra Collection of Algae (ACOI), Department of Life Sciences, University of Coimbra, 3000-456 Coimbra, \\ Portugal; martinscsb@gmail.com (C.B.M.); ferreirajoanadias@gmail.com (J.D.F.); \\ mariajacorreia1@gmail.com (M.J.C.); liliamas@ci.uc.pt (L.M.A.S.) \\ 3 Interdisciplinary Centre of Marine and Environmental Research (CIIMAR), 4450-208 Porto, Portugal; \\ up201510053@fc.up.pt (F.O.); vtr.rms@gmail.com (V.R.); mariana.a.reis@gmail.com (M.R.); \\ raquel.castelobranco.12@gmail.com (R.C.-B.); joaopmorais@gmail.com (J.M.); vmvascon@fc.up.pt (V.V.) \\ 4 Faculty of Sciences, University of Porto, 4450-208 Porto, Portugal \\ 5 Roscoff Culture Collection, Sorbonne University/CNRS, Roscoff Biological Station, 29680 Roscoff, France; \\ probert@sb-roscoff.fr (I.P.); emilie.guilloud@gmail.com (E.G.) \\ 6 Marine Natural Products Team, Nice Institute of Chemistry, UMR 7272 University Nice Côte d'Azur/CNRS, \\ 60103 Nice, France; Mohamed.MEHIRI@unice.fr \\ * Correspondence: sara.soto@isglobal.org; Tel.: +34-93-227-5707
}

Received: 13 May 2019; Accepted: 5 June 2019; Published: 12 June 2019

check for updates

\begin{abstract}
Bacterial biofilms are complex biological systems that are difficult to eradicate at a medical, industrial, or environmental level. Biofilms confer bacteria protection against external factors and antimicrobial treatments. Taking into account that about $80 \%$ of human infections are caused by bacterial biofilms, the eradication of these structures is a great priority. Biofilms are resistant to old-generation antibiotics, which has led to the search for new antimicrobials from different sources, including deep oceans/seas. In this study, 675 extracts obtained from 225 cyanobacteria and microalgae species (11 phyla and 6 samples belonging to unknown group) were obtained from different culture collections: The Blue Biotechnology and Ecotoxicology Culture Collection (LEGE-CC), the Coimbra Collection of Algae (ACOI) from Portugal, and the Roscoff Culture Collection (RCC) from France. The largest number of samples was made up of the microalgae phylum Chlorophyta (270) followed by Cyanobacteria (261). To obtain a large range of new bioactive compounds, a method involving three consecutive extractions (hexane, ethyl acetate, and methanol) was used. The antibiofilm activity of extracts was determined against seven different bacterial species and two Candida strains in terms of minimal biofilm inhibitory concentration (MBIC). The highest biofilm inhibition rates (\%) were achieved against Candida albicans and Enterobacter cloacae. Charophyta, Chlorophyta, and Cyanobacteria were the most effective against all microorganisms. In particular, extracts of Cercozoa phylum presented the lowest $\mathrm{MBIC}_{50}$ and $\mathrm{MBIC}_{90}$ values for all the strains except $C$. albicans.
\end{abstract}

Keywords: Marine sources; Microalgae; Cyanobacteria; Antibiofilm

\section{Introduction}

Bacterial biofilms are formed by aggregates of microorganisms within a complex biological system composed of assemblages of sessile cells adherent to each other or to a surface. Biofilms are 
embedded in an extracellular polymeric substance (EPS) matrix composed mainly of polysaccharides, lipids, proteins, and external DNA (eDNA) [1]. Biofilms provide bacteria protection against external factors such as temperature, $\mathrm{pH}$ variations, desiccation, oxidization, ultraviolet radiation, and metal ions. Furthermore, biofilms are able to evade innate and/or adaptive immune defenses and avoid antimicrobial treatments by several mechanisms [2-4]. Biofilms have the capacity to attach to both biotic and abiotic surfaces, increasing the colonization of medical devices such as urinary and intravenous catheters, mechanical heart valves, endotracheal tubes, and prosthesis joints [5]. In fact, the National Institute of Health (NIH-United States of America) recognizes that $80 \%$ of human infections are caused by bacterial biofilms [6,7]. In the United States, biofilm-related infections affect over 12 million people with an estimated annual economic burden of 6 billion dollars [8].

On the other hand, in the last several decades, antimicrobial resistance (AMR) has increased becoming a serious problem worldwide. Infections caused by drug-resistant bacteria increase the risk of death compared with non-resistant bacteria. However, the emergence of antimicrobial resistant microorganisms has been accompanied by a decrease in the number of new antibacterial agents in the market. Indeed, only two new classes of anti-bacterial drugs have been marketed in the last 60 years: linezolid representing the oxazolidinone group, and daptomycin representing the lipopeptide group [9]. The problem of AMR is further enhanced when current treatments cannot completely eradicate persistent cells that remain inside the biofilm. There is a well-established correlation between bacterial persistence and microorganisms able to form biofilm [10].

In addition, apart from bacterial infections rising in hospitals, the incidences of fungal infections are growing with the development of resistance to conventional antifungal agents [11]. The complex three-dimensional structures of biofilms form a favorable environment for micro niches of Candida species. The biofilm occurrence of these organisms contributing to numerous infections [12]. The fungal pathogen most commonly associated with biofilm infections is Candida albicans, these infections being associated with a high mortality. The most common sites for fungal infections associated with biofilms are the oral cavity, lungs, burn wounds, the lower reproductive tract, the gastrointestinal tract, skin, intravascular and the insertion site of urinary catheters [13]. Thus, C. albicans and C. parapsilosis are two of the Candida species more frequently associated with symptomatic vulvovaginal candidiasis, biofilm formation being essential for the development of this type of infection [14]. These structures confer Candida species a high resistance to the antifungal used in their treatment.

Therefore, the importance of finding new bioactive compounds arises from global bacterial resistance to existing antibiotics. One of the possible sources of new antibiofilm and antimicrobial agents are marine organisms such as macroalgae, microalgae, bryozoans, cnidarians, echinoderms, sponges, molluscs, tunicates, marine fungi, and marine bacteria [15]. Indeed, in 2015, 1340 new marine natural products (MNPs) were reported to have potential efficacy against cancer, viruses, bacteria, fungi, hypertension, high cholesterol, and other diseases [16]. Nevertheless, antimicrobial activity has been detected in 262 marine compounds including alkaloids, terpenoids, lipids, peptides, halogenated compounds, polyketides, isocumarins, nucleosides, and other minority compounds found in MNPs [17]. Several studies have described the antimicrobial activity of a very diverse array of MNPs from marine species [16,18]. In particular, microalgae derivatives may be potentially promising candidates for the development of novel antibacterial drugs because of their ability to combat pathogenic bacteria found throughout the ocean $[19,20]$. These microorganisms have been described as rich sources of several bioactive compounds such as proteins, fatty acids, vitamins, and pigments [20]. Additionally, the coexistence of several species in aquatic systems creates a competitive niche that can lead them to release compounds into the environment in order to facilitate advantage over competitors [21]. These compounds have shown antifungal, antiviral, antialgal, antienzymatic, or antibiotic activity [20]. Lipids such as short-chain fatty acids and PUFAs (polyunsaturated fatty acids) have been associated with antibacterial properties [22,23]. Nonetheless, there is a lack of data related to antibiofilm activity of MNPs obtained from microalgae and cyanobacteria species, with the exception of a single brief reference [24]. 
The aim of the present study was to determine the antibiofilm activity of microalgae and cyanobacteria species against nine biofilm-forming human pathogens, representing the most important Gram-positive, Gram-negative, and fungal species, to search for new bioactive antibiofilm compounds using the biofilm inhibition ratio (\%) and minimal biofilm inhibitory concentration (MBIC) assay.

\section{Results}

The results showed that 205 hexane extracts exhibited the best antibiofilm activity, followed by 195 extracts obtained with methanol and 189 extracts presenting inhibitory activity obtained with ethyl acetate. The rest of the extracts did not show any antibiofilm activity. Nevertheless, no significant activity was reported between methods of extraction $(p>0.05)$ (Table S1). The small differences in activity among the three solvents suggested that the three solvent protocol covers a large range of compounds with different polarities, and it is more effective than extraction with only one solvent.

Figure 1 provides an overview of the biofilm inhibition ratio (\%) per group and solvent. The highest inhibition ratios were reported in C. albicans and E. cloacae in all solvents. Interestingly, C. albicans showed high inhibition rates above $50 \%$ of inhibition in all samples, with the exception of Glaucophyta and Miozoa methanol extracts (28.2\% and $12.55 \%$, respectively) and Rhodophyta hexane extract (34.77\%). High biofilm inhibition ratios, about $35 \%$, were found for E. cloacae. These rates were lower compared to C. albicans but still, more active in comparison with the rest of microorganisms. In the case of E. cloacae, only the methanol extract from the Miozoa phylum showed activity below 35\% (9.38\%). Biofilm inhibition of the nine microorganisms tested was individually analyzed in Figure 2. The inhibition rates in both cases were remarkably high and almost $50 \%$ of inhibitions were above the median value. On the other hand, in the case of S. hominis, only the methanol extract from Miozoa was able to inhibit it up to $64.22 \%$. In addition, extract obtained from Cercozoa and Euglenophyta did not present activity against $S$. aureus.

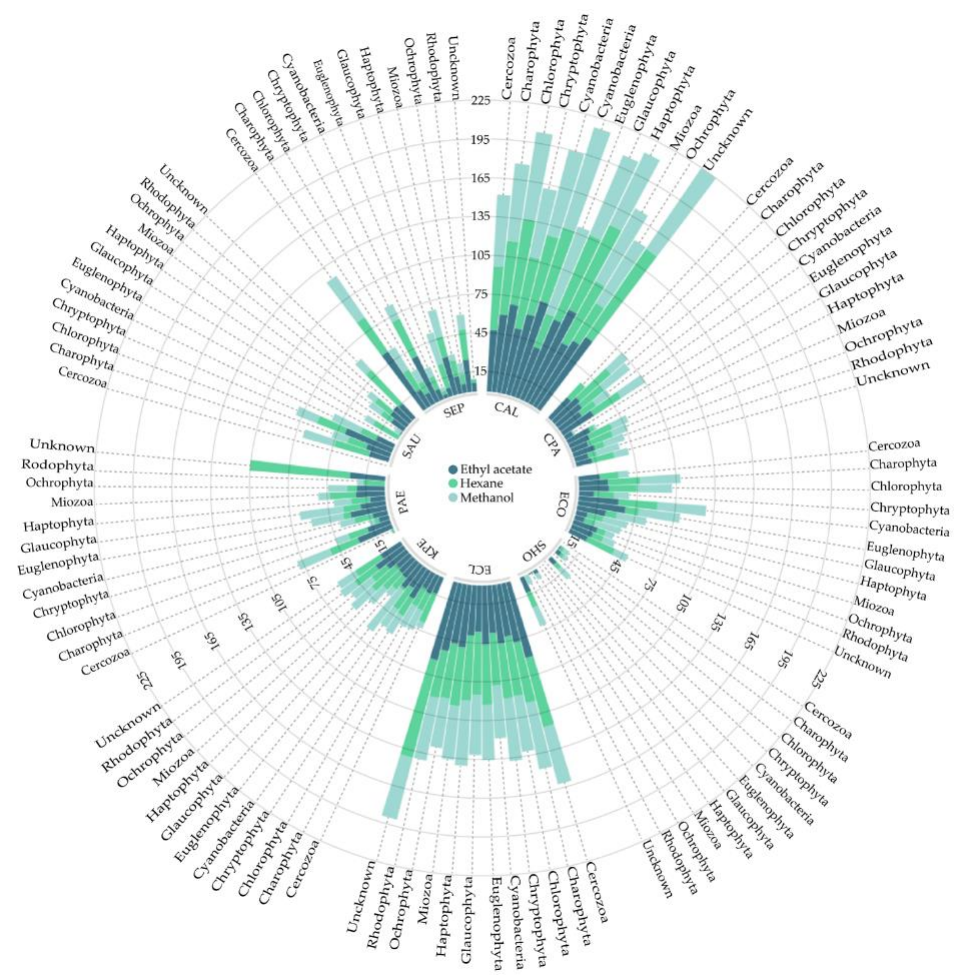

Figure 1. Circular dot plot representing the biofilm inhibition ratio (\%) of each bacterium in relation to the solvent employed (ethyl acetate, hexane, and methanol), according to the microalgae and cyanobacteria phylum. CAL: C. albicans; CPA: C. parapsilopsis; ECO: E. coli; SHO: S. hominis; ECL: E. cloacae; KPE: K. pneumoniae; PAE: P. aeruginosa; SAU: S. aureus; SEP: S. epidermidis. 


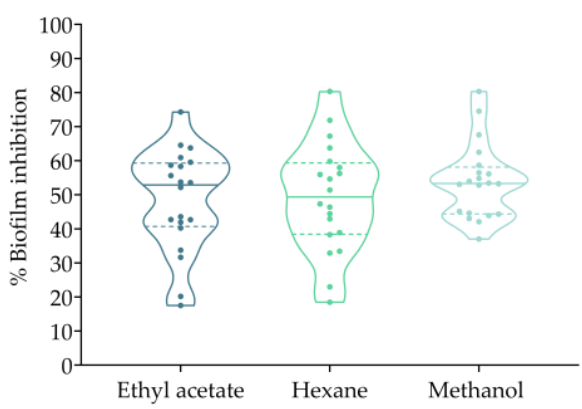

(a)

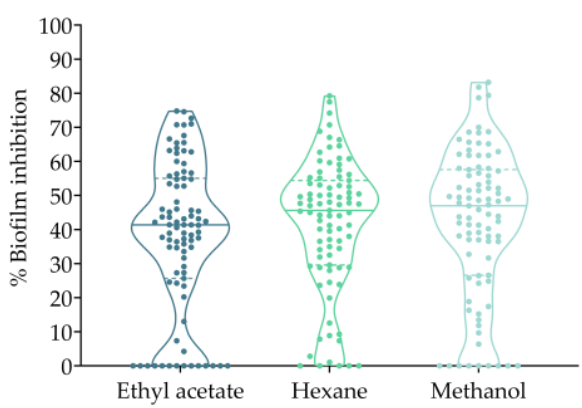

(c)

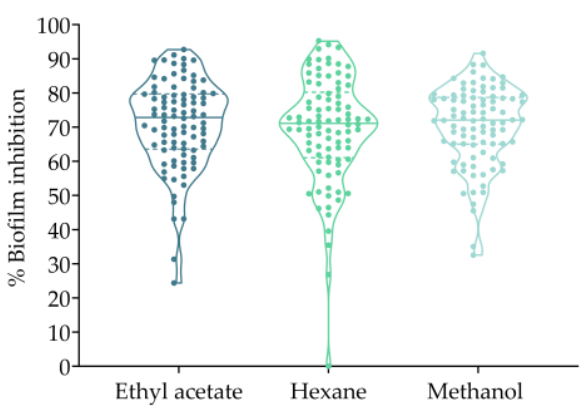

(e)

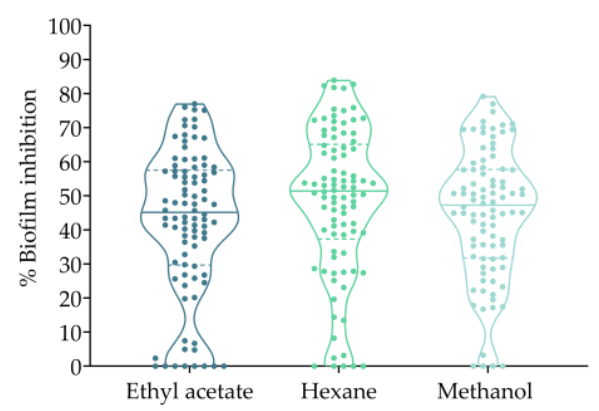

(b)

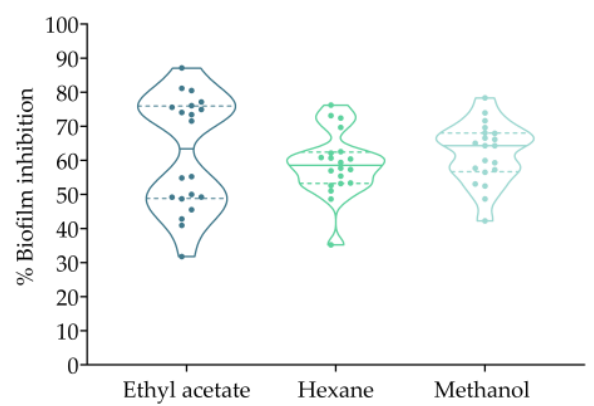

(d)

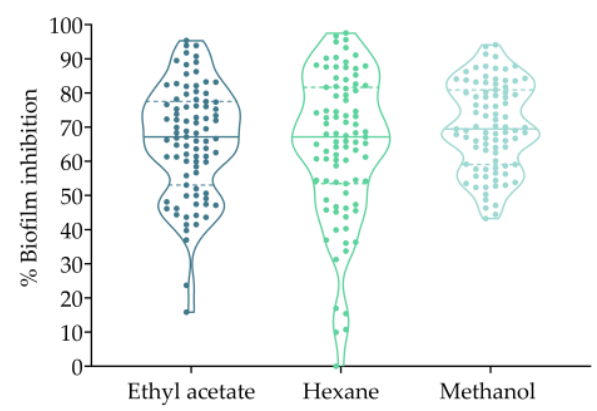

(f)

Figure 2. Individual biofilm inhibition ratios of Charophyta, Chlorophyta, and Cyanobacteria extracts against E. cloacae and C. parapsilopsis, represented as percentages. (a): Charophyta against E. cloacae; (b) Chlorophyta against E. cloacae; (c) Cyanobacteria against E. cloacae; (d) Charophyta against C. albicans; (e) Chlorophyta against C. albicans; (f) Cyanobacteria against C. albicans.

Only the results from phyla with a high number of extracts tested (Charophyta, Chlorophyta and Cyanobacteria) were statistically analyzed. The two-way ANOVA showed that both solvents and phylum significantly influenced the biofilm formation rates $(p<0.001)$ compared to growth control.

To further investigate which phylum and method of extraction (solvent) was more effective in biofilm inhibition, Tukey's multiple comparison test was also performed. Charophyta presented the best inhibition ratios against E. coli, P. aeruginosa, S. aureus, S. epidermidis, and C. parapsilopsis (Tables S2-S4). Cyanobacteria induced biofilm inhibition versus K. pneumoniae and S. hominis. On the other hand, the three phyla presented the same effectiveness against both C. albicans and E. cloacae (Tables S2-S4).

C. albicans and C. parapsilopsis were inhibited by 308 extracts. Biofilm formation among Gram-negative strains was inhibited by 202 extracts (30\%) with equal distribution among species. Among Gram-positive strains, biofilm formation was inhibited by 69 of the 675 samples (10.2\%). 
Cercozoa and the unknown group showed activity at the lowest concentration in all the groups of microorganisms, except for C. albicans. Among all microorganism, the Cryptophyta, Euglenophyta, and Glaucophyta groups showed the best antibiofilm activity.

The Cercozoa presented an $\mathrm{MBIC}_{50}$ of 32 and an $\mathrm{MBIC}_{90}$ of $128 \mu \mathrm{g} / \mathrm{mL}$ in E. coli, K. pneumoniae, E. cloacae, S. aureus, and C. parapsilopsis, whereas among S. epidermidis and S. hominis the $\mathrm{MBIC}_{50}$ and $\mathrm{MBIC}_{90}$ were 64 and $256 \mu \mathrm{g} / \mathrm{mL}$, respectively. P. aeruginosa showed the lowest inhibitory concentrations, with $\mathrm{MBIC}_{50}$ and $\mathrm{MBIC}_{90}$ values of 16 and $64 \mu \mathrm{g} / \mathrm{mL}$, respectively.

The unknown group (represented by two species) presented the highest activity in all microorganisms except for E. cloacae. Thus, the $\mathrm{MBIC}_{50}$ was $64 \mu \mathrm{g} / \mathrm{mL}$, and the $\mathrm{MBIC}_{90}$ was $256 \mu \mathrm{g} / \mathrm{mL}$ for E. coli, P. aeruginosa, and C. parapsilopsis. K. pneumoniae and S. hominis showed $\mathrm{MBIC}_{50}$ and $\mathrm{MBIC}_{90}$ values of 64 and $128 \mu \mathrm{g} / \mathrm{mL}$, respectively. Finally, S. aureus and S. epidermidis presented an $\mathrm{MBIC}_{50}$ of $128 \mu \mathrm{g} / \mathrm{mL}$ and an $\mathrm{MBIC}_{90}$ of $256 \mu \mathrm{g} / \mathrm{mL}$.

Among the Gram-negative bacteria (Table 1), E. cloacae was inhibited by the lowest MBIC values of all the extracts tested. In addition to the results described above, the Cryptophyta and Rhodophyta phyla demonstrated activity against E. cloacae with an $\mathrm{MBIC}_{50}$ and an $\mathrm{MBIC}_{90}$ ranging from 16 to $256 \mu \mathrm{g} / \mathrm{mL}$ and from 16 to $128 \mu \mathrm{g} / \mathrm{mL}$, respectively.

Individually, Rhodophyta showed antibiofilm activity against $E$. coli with $\mathrm{MBIC}_{50}$ and MBIC 90 values of 64 and $512 \mu \mathrm{g} / \mathrm{mL}$, respectively.

The Cryptophyta showed activity against P. aeruginosa with $\mathrm{MBIC}_{50}$ and $\mathrm{MBIC}_{90}$ values of 64 and $512 \mu \mathrm{g} / \mathrm{mL}$, respectively.

Among Gram-positive bacteria (Table 2), S. hominis was inhibited by the lowest MBIC values of all the extracts studied. In addition to Cercozoa and the unknown group, the Miozoa showed $\mathrm{MBIC}_{50}$ and MBIC $_{90}$ values of 128 and $1024 \mu \mathrm{g} / \mathrm{mL}$, respectively. The activity of the Miozoa was only of note in S. hominis. Moreover, the Haptophyta demonstrated activity against $S$. aureus with $\mathrm{MBIC}_{50}$ and $\mathrm{MBIC}_{90}$ values of 128 and $512 \mu \mathrm{g} / \mathrm{mL}$, respectively. Finally, S. epidermidis presented an $\mathrm{MBIC}_{50}$ of $256 \mu \mathrm{g} / \mathrm{mL}$ and an $\mathrm{MBIC}_{90}$ of $1024 \mu \mathrm{g} / \mathrm{mL}$.

Among Candida spp., the greatest activity was reported in C. albicans (Table 3). Three of the 11 groups were able to inhibit biofilm formation with $\mathrm{MBIC}_{50}$ values of $8 \mu \mathrm{g} / \mathrm{mL}$. The lowest activity was reported by the Euglenophyta with an $\mathrm{MBIC}_{50}$ of $8 \mu \mathrm{g} / \mathrm{mL}$ and an $\mathrm{MBIC}_{90}$ of $16 \mu \mathrm{g} / \mathrm{mL}$. Similar results were found with the Cryptophyta showing also an $\mathrm{MBIC}_{50}$ of $8 \mu \mathrm{g} / \mathrm{mL}$ and an $\mathrm{MBIC}_{90}$ of $128 \mu \mathrm{g} / \mathrm{mL}$. Finally, the Glaucophyta presented an $\mathrm{MBIC}_{50}$ and an $\mathrm{MBIC}_{90}$ of 8 and $256 \mu \mathrm{g} / \mathrm{mL}$, respectively. Interestingly, the Euglenophyta and Glaucophyta were only active against biofilm formation in C. albicans.

On the other hand, Rhodophyta species demonstrated activity against C. parapsilopsis with an $\mathrm{MBIC}_{50}$ of $64 \mu \mathrm{g} / \mathrm{mL}$ and an $\mathrm{MBIC}_{90}$ of $512 \mu \mathrm{g} / \mathrm{mL}$.

\section{Discussion}

The present study was designed to determine the effect of new bioactive compounds from microalgae and cyanobacteria species on biofilm formation. We focused on these microorganisms because they are widely distributed in marine and freshwaters and are an important population in all strata, contributing as primary producers in open water systems [25-28]. Crude extracts are a heterogeneous mixture of polar and non-polar compounds. The selection of an efficient method of extraction is important for performing successive assays. For that reason, we used a method combining three different solvents (hexane [non-polar], ethyl acetate [polar], and methanol [polar]) for extracting a wide range of biological samples in order to collect the greatest range of polar and non-polar compounds.

The purpose of hexane is to extract polar compounds from the mixture, such as triacylglycerides (TAG), while methanol and ethyl acetate, polar solvents, can extract many biological compounds (polar and non-polar metabolites), such as fatty acids (FA). 
Table 1. Antibiofilm activity against Gram-negative bacteria of marine natural products. Range: range of concentrations tested; $\mathrm{MBIC}_{50}$ : lowest concentration of the test compound that resulted in $\geq 50 \%$ inhibition of biofilm formation; $\mathrm{MBIC}_{90}$ : lowest concentration of the test compound that resulted in $\geq 90 \%$ inhibition of biofilm formation; GM: geometric mean. MBICs are reported in $\mu \mathrm{g} / \mathrm{mL}$.

\begin{tabular}{|c|c|c|c|c|c|c|c|c|c|c|c|c|c|c|c|c|}
\hline \multirow{2}{*}{ Phylum } & \multicolumn{4}{|c|}{ Escherichia coli } & \multicolumn{4}{|c|}{ Klebsiella pneumoniae } & \multicolumn{4}{|c|}{ Enterobacter cloacae } & \multicolumn{4}{|c|}{ Pseudomonas aeruginosa } \\
\hline & Range & $\mathrm{MBIC}_{50}$ & MBIC $_{90}$ & GM & Range & $\mathrm{MBIC}_{50}$ & $\mathrm{MBIC}_{90}$ & GM & Range & $\mathrm{MBIC}_{50}$ & MBIC $_{90}$ & GM & Range & $\mathrm{MBIC}_{50}$ & $\mathrm{MBIC}_{90}$ & GM \\
\hline Cercozoa & $32-128$ & 32 & 128 & 50.8 & $32-128$ & 32 & 128 & 50.8 & $32-128$ & 32 & 128 & 50.8 & $16-64$ & 16 & 64 & 25.4 \\
\hline Charophyta & $32-2048$ & 256 & 512 & 82.5 & $32-2048$ & 256 & 512 & 69.4 & $16-2048$ & 256 & 512 & 145.3 & 64-2048 & 256 & 1024 & 326.3 \\
\hline Chlorophyta & $8-4096$ & 512 & 1024 & 301.7 & $8-4096$ & 512 & 1024 & 315.2 & $2-4096$ & 256 & 1024 & 288.1 & $8-4096$ & 512 & 1024 & 315.2 \\
\hline Cryptophyta & $16-1024$ & 64 & 1024 & 101.6 & $8-1024$ & 64 & 1024 & 90.5 & $4-256$ & 16 & 256 & 22.6 & $8-512$ & 64 & 512 & 64.0 \\
\hline Cyanobacteria & 8-2048 & 128 & 1024 & 153.7 & $16-2048$ & 256 & 1024 & 197.3 & $8-2048$ & 256 & 512 & 186.6 & $8-2048$ & 128 & 512 & 168.7 \\
\hline Euglenophyta & $64-256$ & 128 & 256 & 128.0 & $64-256$ & 64 & 256 & 101.6 & $64-256$ & 128 & 256 & 128.0 & $64-256$ & 128 & 256 & 128.0 \\
\hline Glaucophyta & 64-1024 & 256 & 1024 & 256.0 & 64-1024 & 256 & 1024 & 256.0 & $64-512$ & 256 & 512 & 228.1 & 64-1024 & 256 & 1024 & 256.0 \\
\hline Haptophyta & $16-512$ & 128 & 512 & 136.3 & $16-512$ & 128 & 512 & 128.0 & $4-512$ & 64 & 512 & 72.6 & $8-512$ & 64 & 256 & 82.3 \\
\hline Miozoa & 32-1024 & 64 & 1024 & 122.2 & $32-1024$ & 64 & 1024 & 116.7 & $16-1024$ & 64 & 1024 & 101.6 & 32-1024 & 64 & 1024 & 111.4 \\
\hline Ochrophyta & $32-1024$ & 128 & 512 & 149.3 & 64-1024 & 128 & 512 & 157.2 & $8-512$ & 64 & 512 & 91.7 & 32-1024 & 128 & 512 & 149.3 \\
\hline Rhodophyta & $32-512$ & 64 & 512 & 90.5 & $32-512$ & 64 & 512 & 90.5 & $4-128$ & 16 & 128 & 22.6 & $32-256$ & 64 & 256 & 80.6 \\
\hline Unknown & $16-256$ & 64 & 256 & 71.8 & $16-128$ & 64 & 128 & 64.0 & $16-128$ & 64 & 128 & 64.0 & $16-256$ & 64 & 256 & 71.8 \\
\hline
\end{tabular}

Table 2. Antibiofilm activity against Gram-positive bacteria of marine natural products. Range: range of concentrations tested; $\mathrm{MBIC}_{50}$ : lowest concentration of the test compound that resulted in $\geq 50 \%$ inhibition of biofilm formation; MBIC 90 : lowest concentration of the test compound that resulted in $\geq 90 \%$ inhibition of biofilm formation; GM: geometric mean. MBICs are reported in $\mu \mathrm{g} / \mathrm{mL}$.

\begin{tabular}{|c|c|c|c|c|c|c|c|c|c|c|c|c|}
\hline \multirow{2}{*}{ Phylum } & \multicolumn{4}{|c|}{ Staphylococcus aureus } & \multicolumn{4}{|c|}{ Staphylococcus epidermidis } & \multicolumn{4}{|c|}{ Staphylococcus hominis } \\
\hline & Range & $\mathrm{MBIC}_{50}$ & MBIC $_{90}$ & GM & Range & $\mathrm{MBIC}_{50}$ & $\mathrm{MBIC}_{90}$ & GM & Range & $\mathrm{MBIC}_{50}$ & MBIC $_{90}$ & GM \\
\hline Cercozoa & $32-128$ & 32 & 128 & 50.8 & $64-256$ & 64 & 256 & 101.6 & $64-256$ & 64 & 256 & 101.6 \\
\hline Charophyta & $64-4096$ & 512 & 1024 & 542.4 & $64-4096$ & 512 & 1024 & 588.1 & 64-4096 & 512 & 1024 & 530.1 \\
\hline Chlorophyta & 8-8192 & 512 & 2048 & 469.2 & 8-8192 & 512 & 2048 & 472.8 & 8-8192 & 256 & 1024 & 291.1 \\
\hline Cryptophyta & $32-2048$ & 128 & 2048 & 203.2 & $32-2048$ & 128 & 2048 & 203.2 & $32-2048$ & 128 & 2048 & 203.2 \\
\hline Cyanobacteria & $16-4096$ & 256 & 2048 & 297 & 16-4096 & 256 & 10,248 & 339.2 & $16-4096$ & 256 & 2048 & 255.3 \\
\hline Euglenophyta & $128-512$ & 256 & 512 & 256 & $128-512$ & 256 & 512 & 256 & $128-512$ & 256 & 512 & 256 \\
\hline Glaucophyta & $128-2048$ & 512 & 2048 & 512 & $128-2048$ & 512 & 2048 & 512 & $128-2048$ & 512 & 2048 & 512 \\
\hline Haptophyta & $32-1024$ & 128 & 512 & 120.8 & $32-1024$ & 256 & 1024 & 170.9 & $32-1024$ & 256 & 1024 & 170.9 \\
\hline Miozoa & $32-2048$ & 128 & 1024 & 194 & 64-2048 & 128 & 1024 & 222.9 & $16-2048$ & 128 & 1024 & 154 \\
\hline Ochrophyta & $128-1024$ & 256 & 1024 & 298.6 & $128-1024$ & 256 & 1024 & 314.4 & $128-1024$ & 256 & 512 & 249.5 \\
\hline Rhodophyta & 64-128 & 128 & 1024 & 181 & 64-128 & 128 & 1024 & 181 & 64-128 & 128 & 1024 & 181 \\
\hline Unknown & $16-256$ & 128 & 256 & 101.6 & $32-256$ & 128 & 256 & 114 & $2-128$ & 64 & 128 & 45.3 \\
\hline
\end{tabular}


Table 3. Antibiofilm activity against Candida spp. of marine natural products. Range: range of concentrations tested; $\mathrm{MBIC}_{50}$ : lowest concentration of the test compound that resulted in $\geq 50 \%$ inhibition of biofilm formation; $\mathrm{MBIC}_{90}$ : lowest concentration of the test compound that resulted in $\geq 90 \%$ inhibition of biofilm formation; GM: geometric mean.

\begin{tabular}{ccccccccc}
\hline \multirow{2}{*}{ Phylum } & \multicolumn{4}{c}{ Candida albicans } \\
\cline { 2 - 8 } & Range & MBIC $_{\mathbf{5 0}}$ & MBIC $_{\mathbf{9 0}}$ & GM & Range & MBIC $_{\mathbf{5 0}}$ & MBIC $_{\mathbf{9 0}}$ & GM \\
\hline Cercozoa & $32-64$ & 32 & 64 & 40.3 & $32-128$ & 32 & 128 & 80.8 \\
Charophyta & $8-128$ & 16 & 64 & 23.7 & $32-4096$ & 256 & 512 & 284 \\
Chlorophyta & $2-2048$ & 32 & 256 & 44.7 & $8-4096$ & 256 & 1024 & 224.6 \\
Cryptophyta & $4-128$ & 8 & 128 & 12.7 & $16-1024$ & 64 & 1024 & 101.6 \\
Cyanobacteria & $2-2048$ & 32 & 256 & 39.6 & $16-4096$ & 256 & 1024 & 186.6 \\
Euglenophyta & $8-16$ & 8 & 16 & 12.7 & $64-256$ & 128 & 256 & 128 \\
Glaucophyta & $4-256$ & 8 & 256 & 16 & $64-1024$ & 256 & 1024 & 256 \\
Haptophyta & $0.5-256$ & 32 & 128 & 20.2 & $16-512$ & 128 & 512 & 90.5 \\
Miozoa & $8-512$ & 32 & 256 & 44.2 & $32-1024$ & 64 & 1024 & 122.2 \\
Ochrophyta & $4-256$ & 32 & 256 & 27.4 & $64-1024$ & 128 & 512 & 165.5 \\
Rhodophyta & $8-64$ & 16 & 64 & 20.2 & $32-512$ & 64 & 512 & 90.5 \\
Unknown & $16-64$ & 32 & 64 & 28.5 & $16-256$ & 64 & 256 & 64 \\
\hline
\end{tabular}

In fact, previous studies have reported that FA have the ability to inhibit biofilm formation. For example, oleic acids block bacterial adhesion in S. aureus [29]. The cis-2-decenoic acid synthetized by P. aeruginosa is able to induce the dispersion of established biofilms and inhibit biofilm formation [30].

Indeed, recent studies have demonstrated that small FA messengers inhibit cell-cell communication, achieving biofilm dispersion and are considered to be a quorum sensing inhibitor [31]. Hence, with three consecutive extraction solvents we were able to collect a wide range of lipids including fatty acids (FA), waxes, sterols, hydrocarbons, ketones, and pigments (carotenoids, chlorophylls, and phycobilins) [32], which have been described as possessing high antibacterial and antibiofilm activity $[23,33]$. The findings of the one-way ANOVA data support the claim that three solvents are necessary to obtain a wide range of molecules.

Only three phyla (Charophyta, Chlorophyta, and Cyanobacteria) were included in the two-way ANOVA analysis due to the number of samples extracted. Nevertheless, the fact that the other phyla showed interesting levels of biofilm inhibition rates (Figure 1) suggests that they are also good candidates for further studies.

The MBIC assay was used to determine the effectiveness of the sample extractions against biofilm producer microorganisms. Among bacteria, lower extract concentrations are needed to inhibit biofilm formation in Gram-negative in comparison with Gram-positive bacteria. Among the yeasts, lower extract concentrations are needed to inhibit biofilm formation in C. albicans compared to C. parapsilopsis. This finding was unexpected, and these extracts are being further investigated in an attempt to elucidate the mechanism underlying the antifungal action of these extracts.

The microalgae and cyanobacteria from which extracts generated were very diverse, and differences were observed in the level of bioactivity of different groups.

It is interesting to note that extracts from the Cercozoa phylum were very active against the eight target microorganisms in this study, except $C$. albicans, which was relatively unaffected. The Cercozoa phylum is a very diverse lineage of unicellular amoeboid organisms that are mostly heterotrophic and that can have a very complex cellular ultrastructure and behavioral patterns. Common examples in marine environments include the biomineralizing radiolarians and Foraminifera. A single relatively minor group within this lineage, the chlorarachniophytes, has acquired green chloroplasts by secondary endosymbiosis at some point in its evolutionary history and therefore qualifies as microalgae. Very little is known about the ecology or metabolism of the 14 described species in this group, but members appear to be good candidates for further investigation in the context of the search for new bioactive molecules. However, these data should be interpreted with caution because the Cercozoa phylum was represented by only three marine culture strains in our study, all of which are relatively difficult to 
grow (low growth rates and maximum cell abundances, adherence to the surface of culture vessels), meaning scale-up of cultures is likely to be challenging.

Several studies have described antimicrobial activities in microalgae and cyanobacteria species [34], but no results about antibiofilm against clinical pathogens, except those from Lauritano et al. [24], have been reported to date. Lauritano's group found two species belonging to the Leptocylindrus genus showing strong antibiofilm activity against $\mathrm{S}$. epidermidis when they are grown in $\mathrm{N}$-starved medium.

This issue may be important since resistance against antimicrobial agents changes depending on the expression of the phenotype. Planktonic microorganisms show greater susceptibility against the current therapies available than biofilm-forming microorganisms $[35,36]$. On the other end of the bioactivity spectrum, the Chlorophyta and Charophyta, which are both lineages of green microalgae, consistently had high average MBIC values. The Chlorophyta are known for their ability to synthesize a variety of bioactive compounds such as lipids and derivative polyunsaturated fatty acids (PUFAs). Two PUFAs, docosahexaenoic acid (DHA) and eicosapentaenoic acid (EPA), have been demonstrated to exhibit antibacterial and antibiofilm properties [36,37]. Extracts from some chlorophyte strains had very low MBIC values and the high average values may be a reflection of the fact that the Chlorophyta was the most represented phylum in our study. Some microalgal groups appear to be specifically active against certain pathogens. For instance, extracts from Rhodophyta species exhibited relatively high antibiofilm activity against E. cloacae, while biofilm formation in C. albicans was particularly sensitive to extracts from Cryptophyta, Euglenophyta, and Glaucophyta (three completely unrelated lineages). Phyla such as Cyanobacteria, Haptophyta and Ochrophyta genera, all of which were fairly well represented in our study, consistently exhibited intermediate average MBIC values. These results can be explained due to several secondary metabolites such as circular or linear lipopeptides, amino acids, FA, macrolides, and amides with antibacterial activity [21].

\section{Materials and Methods}

\subsection{Microalgae and Cyanobacteria Extracts}

A total of 225 species of microalgae and cyanobacteria (belonging to the phyla Cercozoa, Charophyta, Chlorophyta, Cryptophyta, Cyanobacteria, Euglenophyta, Glaucophyta, Haptophyta, Miozoa, Ochrophyta, Rhodophyta, and 2 unknown species) were tested. They were supplied by Blue Biotechnology and Ecotoxicology Culture Collection (LEGE-CC) at CIIMAR, Centro Interdisciplinar de Investigação Marinha e Ambiental (CIIMAR) [38], the Coimbra Collection of Algae, University of Coimbra (ACOI), and the Universite Pierre et Marie Curie-Paris 6 (UPMC). ACOI microalgae strains were collected mainly from freshwater habitats in Portugal. Cyanobacteria were collected mainly from beaches along the Portuguese coast (Atlantic Ocean) but also from brackish and freshwater systems (rivers, lakes, and estuaries). Only one of the cyanobacteria strains tested in this study was isolated from Chile (lake).

Microalgae cultures were performed by CIIMAR, ACOI, and UPMC. Briefly, samples were cultured until stationary phase for 15 or 30 days, depending on the strain, with air bubbling, and temperature and $\mathrm{pH}$ ranged between 20 and $30^{\circ} \mathrm{C}$ and between 6 and 8 , respectively.

The growth media used for microalgae culture were M7, BG-11 (Sigma-Aldrich C3061, Darmstadt, Germany), S2T2, and LC. Each culture was illuminated 14-16 h every day with fluorescent lamps at an intensity of 30-60 $\mu \mathrm{mol} / \mathrm{m} 2 / \mathrm{s}$ or $100-200 \mu \mathrm{mol} / \mathrm{m} 2 / \mathrm{s}$ depending on the strain.

Cyanobacteria strains were cultured for $30-45$ days, depending on the strain, without bubbling, with daily manual shaking between $30 \mathrm{~s}$ and 1 min every day and temperature ranging between 25 and $30^{\circ} \mathrm{C}$. To culture cyanobacteria Z8 [39] and modified Z8 medium supplemented with $25 \mathrm{~g} / \mathrm{L}$ of synthetic sea salts (Tropic Marin, Juliao do Tojal, Portugal) and B12 vitamin were used. The Z8 medium was supplemented because all marine cyanobacterial strains require artificial salts and some of them require the vitamin to grow. Cultures were performed under $14 \mathrm{~h}$ light $/ 10 \mathrm{~h}$ dark cycles with a light intensity of 10-30 mol photons/m2/s). 
Microalgae biomass was collected by centrifugation at $4000 \mathrm{rpm}$ for $15 \mathrm{~min}$. Pellets were frozen at $-80{ }^{\circ} \mathrm{C}$ and lyophilized. Freeze-dried biomass was disrupted using a ceramic mortar, previously exposed to liquid nitrogen or with ultrasounds at $240 \mathrm{~W}, 35 \mathrm{kHz}$ for $5 \mathrm{~min}$.

Sequential extractions from hexane (non-polar), ethyl acetate to methanol (polar) were carried out. Each pellet was extracted by adding $3 \times 20 \mathrm{~mL}$ of each solvent to centrifuge tubes, occasional vortexing and centrifuged at $4500 \mathrm{rpm}$ for $15 \mathrm{~min}$. Supernatant was recovered, transferred to glass vials, and fully dried in the rotary evaporator. Extracts were stored under dark dry conditions until use to avoid hydrolysis of bioactive molecules. The extracts were resuspended in $1 \mathrm{~mL}$ of $6 \%$ dimethyl sulfoxide (DMSO) (Panreac Applichem, Barcelona, Spain) immediately before the bioassay.

\subsection{Microorganisms and Culture Conditions}

Bacterial strains were stored in skim milk (BD) at $-80{ }^{\circ} \mathrm{C}$. In the present study, the strains were characterized in terms of biofilm formation, using the crystal violet protocol, as is shown in Table 4 . E. coli, K. pneumoniae, E. cloacae, and P. aeruginosa were cultured for $24 \mathrm{~h}$ at $37^{\circ} \mathrm{C}$ in aerobic conditions in Luria Broth agar (Condalab, Barcelona, Spain).

Table 4. Biofilm values obtained by crystal violet elution of each microorganism analyzed in this study. $\mathrm{OD}_{580}$ (optical density at $580 \mathrm{~nm}$ ).

\begin{tabular}{ccc}
\hline Microorganism Strains & OD $_{580}$ & Type \\
\hline Escherichia coli & 1.552 & Bacteria \\
Klebsiella pneumoniae & 0.934 & Bacteria \\
Enterobacter cloacae & 0.879 & Bacteria \\
Pseudomonas aeruginosa & 0.701 & Bacteria \\
Staphylococcus aureus & 0.918 & Bacteria \\
Staphylococcus epidermidis & 1.129 & Bacteria \\
Staphylococcus hominis & 0.940 & Bacteria \\
Candida albicans & 1.014 & Yeast \\
Candida parapsilosis & 1.301 & Yeast \\
\hline
\end{tabular}

S. aureus, S. epidermidis, and S. hominis were plated on Columbia agar with $5 \%$ sheep blood agar (Becton Dickinson, Huesca, Spain) for $24 \mathrm{~h}$ at $37^{\circ} \mathrm{C}$ in aerobic conditions.

Candida spp. strains were cultured for $24 \mathrm{~h}$ at $37^{\circ} \mathrm{C}$ in Saboroud Agar (Becton Dickinson, Huesca, Spain).

\subsection{Minimal Biofilm Inhibitory Concentration (MBIC)}

The MBIC assay was performed by the broth microdilution assay described in the CLSI document M7-A7 with some modifications [40]. The culture media used for biofilm formation experiments was M63 supplemented with $0.25 \%$ glucose for E. coli, Luria Bertani broth supplemented with $0.25 \%$ glucose for K. pneumoniae and P. aeruginosa, Tryptic Soy Broth (TSB) supplemented with $0.25 \%$ glucose for Gram-positive bacteria, and Yeast Nitrogen Base (YNB) for Candida spp. These culture media improve the biofilm formation in the corresponding bacterial specie.

For all strains, with an exception of $C$. albicans, two-fold dilution series of each microalgae extract in culture media was inoculated with $50 \mu \mathrm{L}$ of a $0.5 \mathrm{McFarland}$ Standard (corresponding to an inoculum of $5 \times 10^{6}$ cells/well) and incubated for $48 \mathrm{~h}$ at $37^{\circ} \mathrm{C}$ (or $30^{\circ} \mathrm{C}$ in the case of E. coli) in aerobic conditions without shaking. A negative control (culture medium without inoculum) and a positive control (culture medium with inoculum) were included in each plate. All the plates were covered with adhesive foil lids to avoid evaporation.

The biofilm susceptibility assay for P. aeruginosa was performed using the Calgary protocol as described previously [41] with one modification. The bacterial biofilm was formed by immersing the pegs of a modified polystyrene microtiter lid (catalog no. 445497; Nunc TSP system, Nunc, Roskilde, Denmark). 
For Candida spp., a loopful of yeasts, from overnight culture, were washed twice with $3 \mathrm{~mL}$ of phosphate-buffered saline (PBS; pH 7.2; $\mathrm{Ca}^{2+}$ and $\mathrm{Mg}^{2+}$-free), and the optical density of the suspension was adjusted to 0.38 at $520 \mathrm{~nm}$. Two-fold dilution series of each microalgae extract in culture media was inoculated with $50 \mu \mathrm{L}$ of a $0.38 \mathrm{OD}$ (corresponding to an inoculum of $5 \times 10^{6}$ cells/well) and incubated for $48 \mathrm{~h}$ at $37^{\circ} \mathrm{C}$ in aerobic conditions without shaking.

For all microorganisms, after incubation, liquid culture was carefully removed and washed once with PBS and dried at $65{ }^{\circ} \mathrm{C}$ for at least $20 \mathrm{~min}$. Biofilms were stained with $100 \mu \mathrm{L}$ of $1 \%(v / v)$ solution of crystal violet $(\mathrm{CV})$ and incubated for $10 \mathrm{~min}$ at room temperature. Afterwards, the $\mathrm{CV}$ was completely removed, washing once with PBS and heat-fixed at $65^{\circ} \mathrm{C}$ for $60 \mathrm{~min}$.

The CV was eluted by the addition of $200 \mu \mathrm{L}$ of $33 \%$ acetic acid. Biofilm formation was measured at $580 \mathrm{~nm}$ using a Microplate reader (EPOCH). The MBIC was defined as the lowest concentration of drug that resulted in a three-fold decrease of the optical density of $580 \mathrm{~nm}\left(\mathrm{OD}_{580}\right)$ in comparison with the positive growth-control value. The $\mathrm{MBIC}_{50}$ and $\mathrm{MBIC}_{90}$ values were calculated for all the strains.

\subsection{Statical Analysis and Data Processing}

The biofilm inhibition rates were calculated using the equation: $100 \times\left(1-\mathrm{OD}_{580}\right.$ of the test/OD $\mathrm{D}_{580}$ of non-treated control). The $\mathrm{MBIC}_{50}$ and $\mathrm{MBIC}_{90}$ were defined as the lowest concentration that caused $50 \%$ and $90 \%$ inhibition on the formation of biofilm. Statistical analyses were performed in Prism 8 software (GraphPad Software, Inc., La Jolla, CA, USA). One-way ANOVA was used to compare the effects of solvents against bacterial biofilms. Two-way ANOVA with Tukey's test was used to compare the phylum and solvents using OD values. Differences were considered statistically significant when $p<0.05$. A circular dot plot was created with Tableau Software.

\section{Conclusions}

The present study provides initial large-scale evidence that microalgae and cyanobacteria are rich sources of substances with antibiofilm activity. Results demonstrated the importance of (1) employing a comprehensive extraction protocol in order to increase the chances of detecting bioactive substances; (2) testing extracts against a range of target microorganisms (because sensitivity to individual extracts differed among the organisms tested here); and (3) testing extracts from a broad range of source organisms (because significant differences were observed in the level of activity of extracts from different microalgal groups). Large-scale screening programs like this are extremely useful for identifying organisms that warrant further study as producers of bioactive substances of interest. Overall, the findings of this study provide insights for new opportunities provided by oceans and freshwater systems in the fight against biofilm infections. Further studies will be made in order to determine the active compounds responsible of the antibiofilm activity as well as their toxicity to mammal cells because at extract level toxicity could be due to other components different from the active one.

Supplementary Materials: The following are available online at http:/www.mdpi.com/2079-6382/8/2/77/s1. Table S1: Three methods of extraction analyzed by one-way ANOVA. DF: degrees of freedom; P value: $p<0.05$ were considered statistically significant. Table S2: Results of Gram-negatives strains comparing with treatment (phylum) and method of extraction (solvent). Two-way ANOVA followed by post hoc Tukey's test were used. MD: mean difference; SD: standard error of the difference; CI of diff: confidence interval of difference 95\%; P value: $p<0.05$ were considered statistically significant. Table S3: Results of Gram-positives strains comparing with treatment (phylum) and method of extraction (solvent). Two-way ANOVA followed by post hoc Tukey's test were used. MD: mean difference; SD: standard error of the difference; CI of diff: confidence interval of difference $95 \%$; P value: $p<0.05$ were considered statistically significant. Table S4: Results of Candida spp. comparing with treatment (phylum) and method of extraction (solvent). Two-way ANOVA followed by post hoc Tukey's test were used. MD: mean difference; SD: standard error of the difference; CI of diff: confidence interval of difference $95 \%$; $P$ value: $p<0.05$ were considered statistically significant.

Author Contributions: Study design: S.M.S.; MBIC assays: V.C., Y.L., and Y.G.; statistical analysis: V.C. and Y.L.; sample collection, extraction, and isolation: C.B.M., J.D.F., M.J.C., L.M.A.S., F.O., V.R., M.R., R.C.-B., J.M., V.V., I.P., E.G., and M.M.; original draft preparation: V.C. and S.M.S. All authors contributed equally to the review and editing of the manuscript. 
Funding: This work was funded by the European Commission under the H2020 program, NoMorFilm Project (Grant Agreement 634588).

Conflicts of Interest: The authors declare no conflict of interest.

\section{References}

1. Flemming, H.-C.; Wingender, J.; Szewzyk. The biofilm matrix. Nat. Rev. Microbiol. 2010, 8, $623-633$. [CrossRef] [PubMed]

2. Roilides, E.; Simitsopoulou, M.; Katragkou, A.; Walsh, T.J. How biofilms evade host defenses. Microbiol. Spectr. 2015, 3, 1-10. [CrossRef]

3. Domenech, M.; Ramos-Sevillano, E.; García, E.; Moscoso, M.; Yuste, J. Biofilm formation avoids complement immunity and phagocytosis of Streptococcus pneumoniae. Infect. Immun. 2013, 81, 2606-2615. [CrossRef] [PubMed]

4. Stewart, P.S. Antimicrobial Tolerance in Biofilms. Microbiol. Spectr. 2015, 3, 1-30. [CrossRef] [PubMed]

5. Donlan, R.M.; Costerton, J.W. Biofilms: Survival mechanisms of clinically relevant microorganisms. Clin. Microbiol. Rev. 2002, 15, 167-193. [CrossRef] [PubMed]

6. Mclean, R.J.C.; Lam, J.S.; Graham, L.L. Training the biofilm generation-A tribute to J. W. Costerton. J. Bacteriol. 2012, 194, 6706-6711. [CrossRef] [PubMed]

7. Garrett, T.R.; Bhakoo, M.; Zhang, Z. Bacterial adhesion and biofilms on surfaces. Prog. Nat. Sci. 2008, 18, 1049-1056. [CrossRef]

8. Gbejuade, H.O.; Lovering, A.M.; Webb, J.C. The role of microbial biofilms in prosthetic joint infections-A review. Acta Orthop. 2015, 86, 147-158. [CrossRef]

9. Coates, A.R.; Halls, G.; Hu, Y. Novel classes of antibiotics or more of the same? Br. J. Pharm. 2011, 163, $184-194$. [CrossRef] [PubMed]

10. Cohen, N.R.; Lobritz, M.A.; Collins, J.J. Microbial persistence and the road to drug resistance. Cell Host Microbe 2013, 13, 632-642. [CrossRef] [PubMed]

11. Brown, G.D.; Denning, D.W.; Gow, N.A.R.; Levitz, S.M.; Netea, M.G.; White, T.C. Hidden killers: Human fungal infections. Sci. Transl. Med. 2012, 4, 165rv13. [CrossRef] [PubMed]

12. Silva-Dias, A.; Miranda, I.M.; Branco, J.; Monteiro-Soares, M.; Pina-Vaz, C.; Rodrigues, A.G. Adhesion, biofilm formation, cell surface hydrophobicity, and antifungal planktonic susceptibility: Relationship among Candida spp. Front. Microbiol. 2015, 6, 205. [CrossRef] [PubMed]

13. Iñigo, M.; Del Pozo, J.L. Fungal biofilms: From bench to bedside. Rev. Esp. Quim. 2018, 31 (Suppl. 1), $35-38$.

14. Rodríguez-Cerdeira, C.; Gregorio, M.C.; Molares-Vila, A.; López-Barcenas, A.; Fabbrocini, G.; Bardhi, B.; Sinani, A.; Sánchez-Blanco, E.; Arenas-Guzmán, R.; Hernandez-Castro, R. Biofilms and vulvovaginal candidiasis. Colloids Surf. B Biointerfaces 2019, 174, 110-125. [CrossRef] [PubMed]

15. Motuhi, S.-E.; Mehiri, M.; Payri, C.; La Barre, S.; Bach, S. Marine natural products from New Caledonia-A Review. Mar. Drugs 2016, 14, 58. [CrossRef] [PubMed]

16. Blunt, J.W.; Copp, B.R.; Keyzers, R.A.; Munro, M.H.G.; Prinsep, M.R. Marine natural products. Nat. Prod. Rep. 2017, 34, 235-294. [CrossRef]

17. Choudhary, A.; Naughton, L.; Montánchez, I.; Dobson, A.; Rai, D. Current status and future prospects of marine natural products (MNPs) as antimicrobials. Mar. Drugs 2017, 15, 272. [CrossRef]

18. Blunt, J.W.; Copp, B.R.; Munro, M.H.G.; Northcote, P.T.; Prinsep, M.R. Marine natural products. Nat. Prod. Rep. 2010, 27, 165-237. [CrossRef]

19. Shannon, E.; Abu-Ghannam, N. Antibacterial derivatives of marine algae: An overview of pharmacological mechanisms and applications. Mar. Drugs 2016, 14, 81. [CrossRef]

20. De Morais, M.G.; Vaz, B.D.S.; De Morais, E.G.; Costa, J.A.V. Biologically active metabolites synthesized by microalgae. Biomed. Res. Int. 2015, 2015, 835761. [CrossRef]

21. Singh, S.; Kate, B.N.; Banecjee, U.C. Bioactive compounds from cyanobacteria and microalgae: An overview. Crit. Rev. Biotechnol. 2005, 25, 73-95. [CrossRef] [PubMed]

22. Bergsson, G.; Hilmarsson, H.; Thormar, H. Antibacterial, antiviral and antifungal activities of lipids. In Lipids and Essential Oils As Antimicrobial Agents; Thormar, H., Ed.; John Wiley \& Sons Ltd.: Chichester, UK, 2010.

23. Michalak, I.; Chojnacka, K. Algae as production systems of bioactive compounds. Eng. Life Sci. 2013, 2013, 1-29. [CrossRef] 
24. Lauritano, C.; Andersen, J.H.; Hansen, E.; Albrigtsen, M.; Escalera, L.; Esposito, F.; Helland, K.; Hanssen, K. Ø.; Romano, G.; Ianora, A. Bioactivity Screening of Microalgae for Antioxidant, Anti-Inflammatory, Anticancer, Anti-Diabetes, and Antibacterial Activities. Front. Mar. Sci. 2016, 3, 1405. [CrossRef]

25. Sanchez-Baracaldo, P. Origin of marine planktonic cyanobacteria. Sci. Rep. 2015, 5, 17418. [CrossRef] [PubMed]

26. Field, C.B. Primary Production of the Biosphere: Integrating Terrestrial and Oceanic Components. Science 1998, 281, 237-240. [CrossRef] [PubMed]

27. Jaubert, M.; Bouly, J.P.; Ribera d'Alcalà, M.; Falciatore, A. Light sensing and responses in marine microalgae. Curr. Opin. Plant. Biol. 2017, 37, 70-77. [CrossRef]

28. Ramirez, J.; Brown, R.; Rainey, T. A review of hydrothermal liquefaction bio-crude properties and prospects for upgrading to transportation fuels. Energies 2015, 8, 6765-6794. [CrossRef]

29. Stenz, L.; Franãßois, P.; Fischer, A.; Huyghe, A.; Tangomo, M.; Hernandez, D.; Cassat, J.; Linder, P.; Schrenzel, J.; François, P. Impact of oleic acid (cis-9-octadecenoic acid) on bacterial viability and biofilm production inStaphylococcus aureus. FEMS Microbiol. Lett. 2008, 287, 149-155. [CrossRef]

30. Davies, D.G.; Marques, C.N.H. A fatty acid messenger is responsible for inducing dispersion in microbial biofilms. J. Bacteriol. 2009, 191, 1393-1403. [CrossRef]

31. Marques, C.N.H.; Davies, D.G.; Sauer, K. Control of biofilms with the fatty acid signaling molecule cis-2-Decenoic acid. Pharmaceuticals 2015, 8, 816-835. [CrossRef]

32. Cuellar-Bermudez, S.P.; Aguilar-Hernandez, I.; Cardenas-Chavez, D.L.; Ornelas-Soto, N.; Romero-Ogawa, M.A.; Parra-Saldivar, R. Extraction and purification of high-value metabolites from microalgae: Essential lipids, astaxanthin and phycobiliproteins. Microb. Biotechnol. 2015, 8, 190-209. [CrossRef] [PubMed]

33. Ivanova, A.J.; Nechev, I.; Tsvetkova, H.; Najdenski, K.; Popov, S.S. Compounds with antibacterial activity from the freshwater alga Spirogyra crassa. Genet. Plant. Physiol. 2011, 1, 31-37. [CrossRef]

34. Niedermeyer, T.H. Anti-infective natural products from Cyanobacteria. Planta Med. 2015, 81, $1309-1325$. [CrossRef] [PubMed]

35. Ciofu, O.; Rojo-Molinero, E.; Macià, M.D.; Oliver, A. Antibiotic treatment of biofilm infections. APMIS 2017, 125, 304-319. [CrossRef] [PubMed]

36. Høiby, N.; Bjarnsholt, T.; Givskov, M.; Molin, S.; Ciofu, O. Antibiotic resistance of bacterial biofilms. Int. J. Antimicrob. Agents 2010, 35, 322-332. [CrossRef] [PubMed]

37. Sun, M.; Zhou, Z.; Dong, J.; Zhang, J.; Xia, Y.; Shu, R. Antibacterial and antibiofilm activities of docosahexaenoic acid (DHA) and eicosapentaenoic acid (EPA) against periodontopathic bacteria. Microb. Pathog. 2016, 99, 196-203. [CrossRef] [PubMed]

38. Ramos, V.; Morais, J.; Castelo-Branco, R.; Pinheiro, Â.; Martins, J.; Regueiras, A.; Pereira, A.L.; Lopes, V.R.; Frazão, B.; Gomes, D.; et al. Cyanobacterial diversity held in mBRCs as a biotechnological asset: The case study of the newly established LEGE Culture Collection. J. Appl. Phycol. 2018, 30, 1437-1451. [CrossRef] [PubMed]

39. Kotai, J. Instructions for the Preparation of Modiwed Nutrient Solution Z8 for Algae, Vol 11/69; Norwegian Institute for Water Research: Oslo, Norway, 1972; Volume 11, p. 5.

40. Clinical and Laboratory Standards Institute (CLSI). Performance Standards for Antimicrobial Susceptibility Testing; 24th Information Supplement, M100-S24, vol. 34, no. 1; Clinical and Laboratory Standards Institute: Wayne, PA, USA, 2014.

41. Ali, L.; Khambaty, F.; Diachenko, G. Investigating the suitability of the Calgary biofilm device for assessing the antimicrobial efficacy of new agents. Bioresour. Technol. 2006, 97, 1887-1893. [CrossRef]

(C) 2019 by the authors. Licensee MDPI, Basel, Switzerland. This article is an open access article distributed under the terms and conditions of the Creative Commons Attribution (CC BY) license (http://creativecommons.org/licenses/by/4.0/). 